\title{
Determination of Mixing Time in a Ladle-Refining Process Using Optical Image Processing
}

\author{
Teng-Yi KUO and Jui-Chao KUO* \\ Department of Materials Science and Engineering, National Cheng-Kung University, Tainan 701, Taiwan. E-mail: jckuo@mail. \\ ncku.edu.tw
}

(Received on May 6, 2011; accepted on June 21, 2011)

\begin{abstract}
Water model experiments were performed to measure the mixing time and to investigate the effect of nozzle depth in a ladle-refining process. The depth of the submergence nozzle was varied by $6.0,7.2$, and $8.4 \mathrm{~cm}$, which correspond to fractional depths of $0.5,0.6$, and 0.7 , respectively. A new technique was proposed in the present study to measure the mixing time using optical image processing. The mixing time for fractional depths of $0.5,0.6$, and 0.7 determined is 26,19 , and $20 \mathrm{sec}$, respectively. The gas dispersions in the plume zone are distributed asymmetrically. An increase in the nozzle depth, which enhances recirculation speeds, leads to a decrease in mixing time.
\end{abstract}

KEY WORDS: mixing time; water model; optical image processing.

\section{Introduction}

An improvement in steel quality plays an important role in the production of clean steel. Clean steel has a very low content of impure elements and inclusions. Inclusions are known to have an adverse effect on steel quality and properties. Gas injection is one of methods developed to remove inclusions from liquid steel. It is usually employed in secondary metallurgy processes and continuous casting to achieve a homogeneous distribution of temperature and composition, and to eliminate second phases and dissolved impurities. ${ }^{1-4)}$ Earlier studies on the water model reported particle removal using gas bubble flotation. ${ }^{5-10)}$

To analyze phenomena associated with the agitation of liquid baths, the determination of the mixing time is very important. ${ }^{11-21)}$ A number of studies ${ }^{18-22)}$ have reported that the value of the mixing time obtained experimentally is dependent on the location of the measuring probe and the tracer injection. Murthy has shown that the degree of mixing in the bath changes as the operating conditions is varied. ${ }^{17)}$

Gas injection operation is conducted to obtain chemical and thermal homogenization. It plays a significant role in achieving the minimum mixing time at the optimum process parameters. The mixing time refers to the time required for homogeneity to be achieved in all parts of the bath. Therefore, the mixing time can be considered as a representative parameter of the mixing phenomena of the bath in chemical and metallurgical processes. The electrical conductivity technique is usually applied for the determination of mixing time by measuring the concentration changes of an added tracer (for example, $\mathrm{NaCl}$ solution) in a liquid bath as a function of time.

Therefore, we propose a new technique in the current study using optical image processing to determine the mixing time for the injection of gas in ladle.

\section{Experimental Set-up}

The fluid-flow phenomena in a ladle-refining process were simulated physically in the current study using a watermodeling technique. The refining ladle was represented by a transparent, plexi-glass vessel. During the experiment, a series of photographs was taken to examine the flow pattern in the refining process.

The experimental set-up for the determination of mixing time is schematically shown in Fig. I. The system of the water model consists of a cylindrical plexi-glass vessel containing tap water at room temperature. The vessel is $100 \mathrm{~mm}$ wide, $270 \mathrm{~mm}$ high, and $2 \mathrm{~mm}$ thick. Before injection, 300000 spherical particles of low-density polyethylene (with a density of $0.92 \mathrm{~g} / \mathrm{cm}^{3}$ ) were on the top surface. This is due to that the density of PE is smaller than that of water. Air was injected into the bath through a centric top nozzle using a compressor, and the flow rate is $4 \mathrm{~L} / \mathrm{min}$. The nozzle which has an inner diameter of $1.2 \mathrm{~mm}$ was located 36,48 , and $58 \mathrm{~mm}$ above the bottom part, respectively. The nozzle depths at 36,48 , and $58 \mathrm{~mm}$ correspond to $0.5,0.6$, and 0.7 factional depths of nozzle submergence, respectively.

In the experiments, fluid-flow phenomena were simulated by recording the trajectories of the particles in the quasi-2D area. To simulate a quasi-2D projected area, light is limited to pass through two narrow parallel planes as shown in Fig 1. A CCD camera, Canon EOS D40 with a $2592 \times 3888$ pixel resolution, was used to record photos every $0.5 \mathrm{sec}$ during the measurement time of $200 \mathrm{sec}$. The aperture of 2.8 is employed due to a very low illumination on the particles during taking photos. Thus, the aperture is set to a small number, that is, a lot of light get into the camera. It enhances the brightness and contrast of images which is of importance for later image processing. 

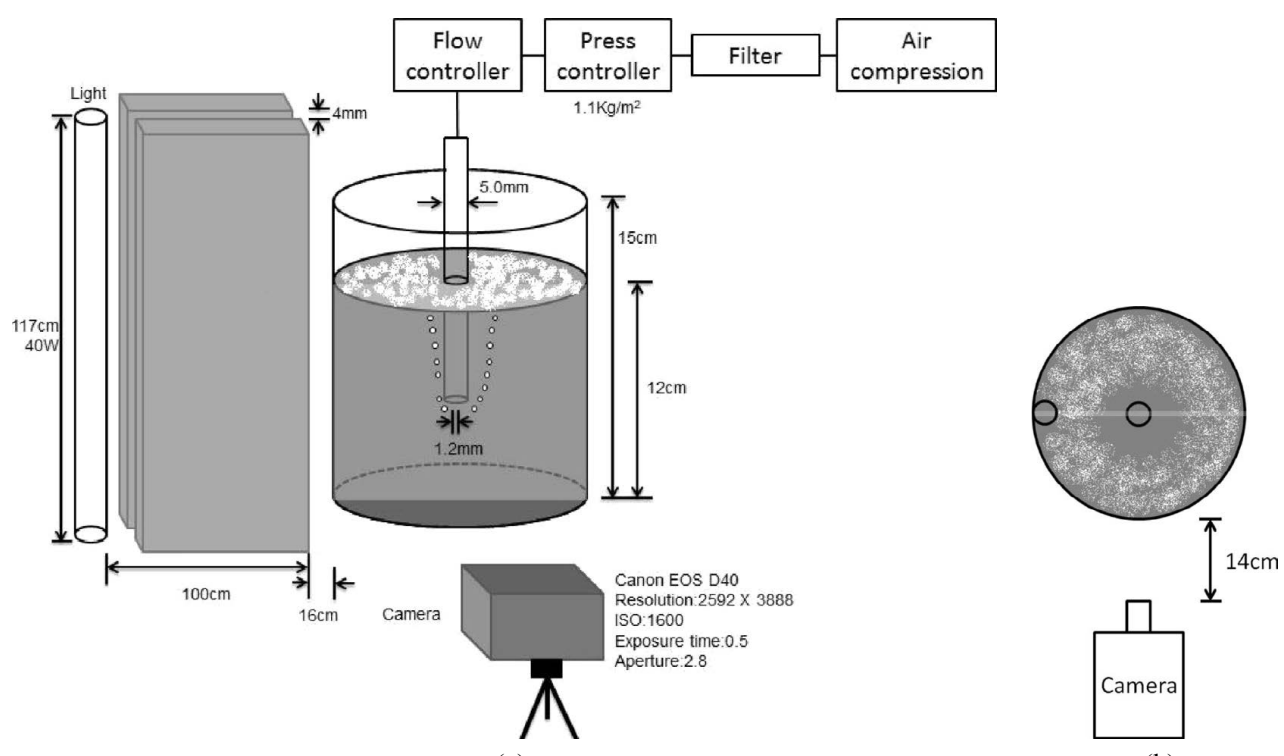

(a)

(b)

Fig. 1. (a) Schematic illustration of the experimental set-up of the measurement of mixing time. (b) Top view of the set-up.

\section{Results and Discussion}

\subsection{Determination of Mixing Time}

In the current study, we proposed a new technique to measure the mixing time using optical image processing. The concept of the application of this technique is based on the distribution of tracer particles in a bath as shown in Fig. 2(g). Chemical homogenization is obtained as the distribution of particles is steady, which means that the flow patterns do not change. Therefore, recording images of the particle distribution every $5 \mathrm{sec}$ and summing up the gray scale value of each pixel in the digital image as a function of time are possible. In the case of $6.0 \mathrm{~cm}$ depth, the histograms of the digital image at 10, 20, 30, and $40 \mathrm{sec}$ are shown in Fig. 3(a). Except for that at $10 \mathrm{sec}$, the distribution of the gray scale from 0 to 4 is almost the same and can be considered as noise. Figure 4(a) shows the filtered image in which each pixel is in black as the value of the gray scale falls below 4, which is called "noise." In the following calculation, the sum of the gray scale of the "noise" points is abstracted from that of each point in the image.

The sum of the gray scale as a function of time is shown in Fig. 5(a) in which the dashed line refers to experiment data. A Gauss function is used to fit the experiment data, which is represented as a solid line. As time increases, the value approaches a constant value. Therefore, the mixing time is defined when the fitting curve arrives at a constant value. The mixing time for depths of $6.0,7.2$, and $8.4 \mathrm{~cm}$ is 26,19 , and $20 \mathrm{sec}$, respectively.

\subsection{Flow Patterns in the Ladle}

Figure 2 shows examples of the negative images of the tracer particles during injection. The nozzle is in the center of the vessel, and an asymmetric plume zone is found in the middle area with a dark black color, which indicates bubbles as shown in Fig. 2(a). As the depth of the nozzle is increased from 6.2 to $8.4 \mathrm{~cm}$, the height of the plume is also increased, but the width does not change in Figs. 2(a)-2(b). During gas injection, PE tracer particles are introduced into the bath from the top surface. Further, flow patterns are not symmet-

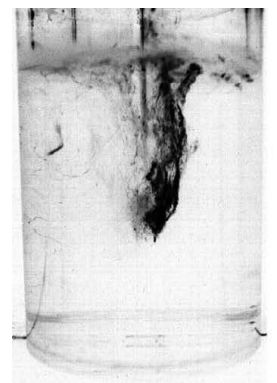

(a) $\mathrm{d}=6.0 \mathrm{~cm}, \mathrm{t}=0 \mathrm{~s}$

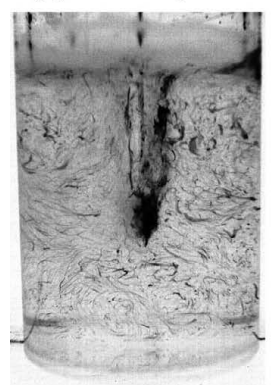

(d) $\mathrm{d}=6.0 \mathrm{~cm}, \mathrm{t}=50 \mathrm{~s}$

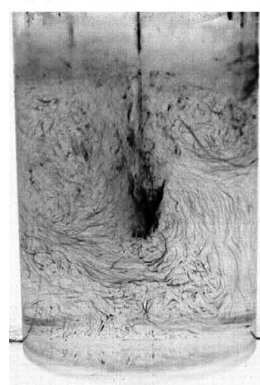

(g) $\mathrm{d}=6.0 \mathrm{~cm}, \mathrm{t}=150 \mathrm{~s}$

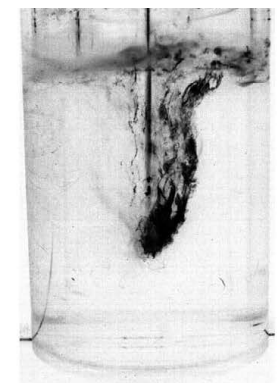

(b) $\mathrm{d}=7.2 \mathrm{~cm}, \mathrm{t}=0 \mathrm{~s}$

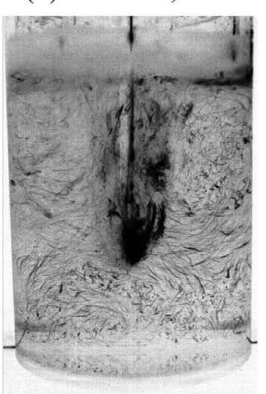

(e) $\mathrm{d}=7.2 \mathrm{~cm}, \mathrm{t}=50 \mathrm{~s}$

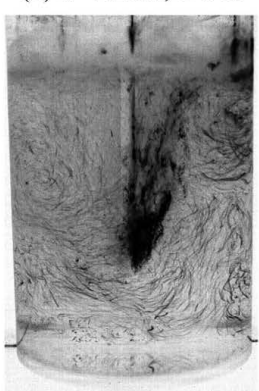

(h) $\mathrm{d}=7.2 \mathrm{~cm}, \mathrm{t}=150 \mathrm{~s}$

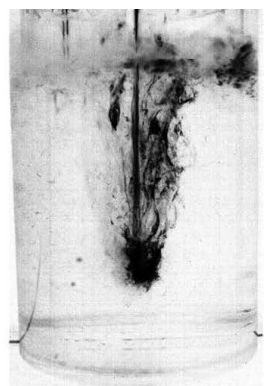

(c) $\mathrm{d}=8.4 \mathrm{~cm}, \mathrm{t}=0 \mathrm{~s}$

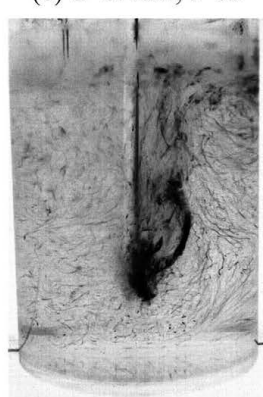

(f) $\mathrm{d}=8.4 \mathrm{~cm}, \mathrm{t}=50 \mathrm{~s}$

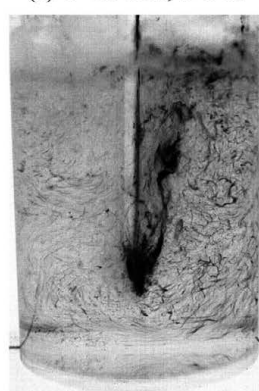

(i) $\mathrm{d}=8.4 \mathrm{~cm}, \mathrm{t}=150 \mathrm{~s}$
Fig. 2. Photographs of flow patterns (d: depth and t: time). Fractional depth of nozzle submergence $=$ (a) 0.5 , (b) 0.6 , (c) 0.7 .

ric about the centric nozzle. Similar flow patterns are obtained for an injection time of 50 and $150 \mathrm{sec}$ as shown in Figs. 2(d)-2(i).

The main flow-related phenomena are shown in Fig. 6 for 




(a)

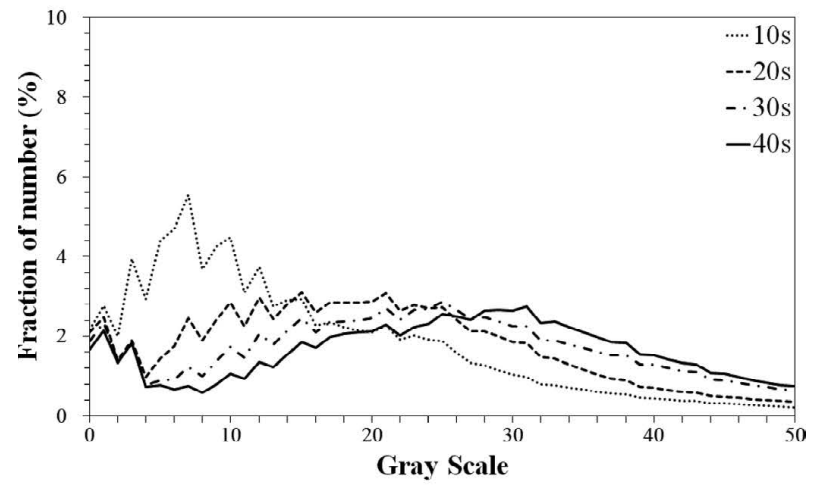

(b)

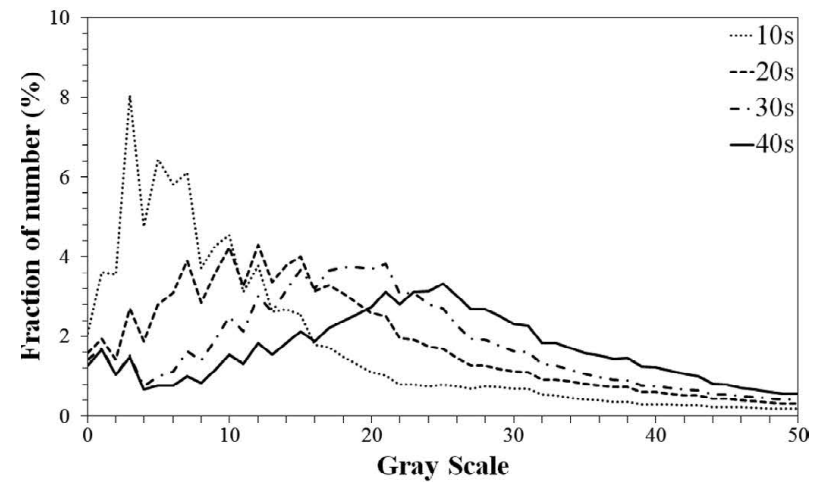

(c)

Fig. 3. Gray scale histogram of photographs measured experimentally for a time in the range of 0 and $50 \mathrm{sec}$ at depths of (a) 6.0 , (b) 72 , and (c) $8.4 \mathrm{~cm}$ (total: sum of the gray scale value of each point and $\mathrm{N}$ : sum of the corresponding gray scale).



(a)

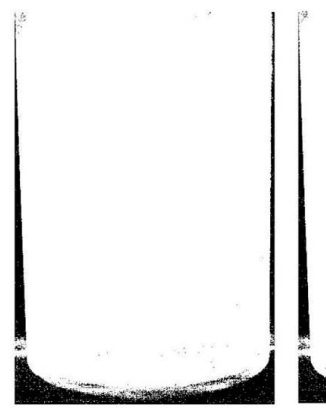

(b) (a)



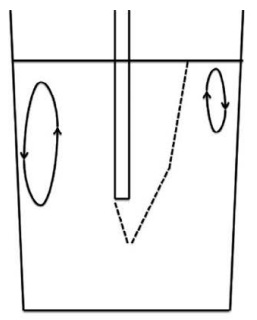

(b)



(c)
Fig. 6. Schematic illustration of the flow patterns at depths of (a) 6.0 , (b) 7.2 , and (c) $8.4 \mathrm{~cm}$ (Dashed line: plume zone).

the nozzle positions of $6.0,7.2$, and $8.4 \mathrm{~cm}$ from the top surface. The gas dispersions are formed in the plume zone, and their distribution is asymmetric about the nozzle. At first, 
the gas bubble moves upward and transports the tracer particles into the upper portion in Fig. 6(a). The uneven flow discharge from the central nozzle may cause asymmetric and unsteady flow in the vessel or periodic oscillations of the level. ${ }^{23)}$ The flow in the vessel is quantified by measuring the magnitude of the top surface level fluctuations, that is, the flow pattern shape. An increase in the depth of the nozzle results in an enlargement of flow shape as shown in Figs. 6(a)-6(b).

In a plume zone, the carrier gas rises to the free surface and induces recirculation flows of fluid within the vessel. According to the macroscopic plume model proposed by Sahai and Guthrie, ${ }^{24)}$ the average velocity of a plume, $U_{p}$, is estimated by

$$
U_{P}=k \cdot \frac{Q^{1 / 3} L^{1 / 4}}{R^{1 / 3}}
$$

where $Q$ is the gas flow, $L$ is the liquid depth, and $R$ is the ladle radius.

The flow patterns generated in these cases are very similar. According to Eq. (1), an increase in the nozzle depth causes the recirculation speeds to increase. Therefore, this results in a reduction in mixing time.

\section{Conclusions}

A new technique was demonstrated to measure mixing time using image processing. The mixing time for 6.0, 7.2, and $8.4 \mathrm{~cm}$ depths is 26,19 and $20 \mathrm{sec}$, respectively. The distribution of gas dispersions in the plume zone is asymmetric. An increase in the nozzle depth, which enhances recirculation speeds, results in a reduction in mixing time.

\section{Acknowledgements}

This work was partially supported by the National Science Council of Taiwan under the grant number: NSC 98-2221-E-006-081-MY2 and China Steel Corporation (CSC).

\section{REFERENCES}

1) L. Zhang and S. Taniguchi: Int. Mater. Rev., 45 (2000), 59.

2) M. Iguchi, J. Yoshida, T. Shimizu and Y. Mizuno: ISIJ Int., 40 (2000), 685

3) Z. Wang, K. Mukai, Z. Ma, M. Nishi, H. Tsukamoto and F. Shi: ISIJ Int., 39 (1999), 795.

4) D. Mazumdar and R. I. L. Guthrie: ISIJ Int., 35 (1995), 1.

5) H. J. Schulze: Miner. Process. Extrac. Metall. Rev., 5 (1989), 43.

6) L. Wang, H. G. Lee and P. Hayes: ISIJ Int., 36 (1996), 17.

7) X. Zheng, P. C. Hayes and H. G. Lee: ISIJ Int., 37 (1997), 1091.

8) P. Wei, K. I. Uemura and S. Koyama: Tetsu-to-Hagané, 78 (1992), 1361.

9) A. G. Szekely: Metall. Trans. B, 7 (1976), 259

10) N. Ahmed and G. J. Jamson: Miner. Process. Extrac. Metall. Rev., 5 (1989), 77

11) K. Nakanishi, T. Fujii and J. Szekely: Ironmaking Steelmaking, 3 (1975), 193.

12) J. Szekely, T. Lehner and C. W. Chang: Ironmaking Steelmaking, 6 (1979), 285.

13) S. Asai, T. Okamoto, J. C. Heand and I. Muchi: Trans. Iron Steel Inst. Jpn., 23 (1983), 43.

14) M. Sano and K. Mori: Trans. Iron Steel Inst. Jpn., 23 (1983), 169.

15) J. Mietz and F. Oeters: Steel Res., 59 (1988), 52.

16) G. G. K. Murthy, S. P. Mehrotra and A. Ghosh: Metall.Trans. B, 19B (1988), 839.

17) G. G. K. Murthy: ISIJ Int., 29 (1989), 49.

18) U. P. Sinha and M. J. McNallan: Metall. Trans. B, 16B (1985), 850

19) D. Mazumdar and R. I. L. Guthrie: Ironmaking Steelmaking, 12 (1985), 256.

20) D. Mazumdar and R. I. L. Guthrie: Metall. Trans. B, 17B (1986), 725.

21) J. Mietz and F. Oeters: Steel Res., 58 (1987), 446.

22) C. W. Kuo, S. M. Yang, J. H. Chen, G. H. Lai, Y. C. Chen, Y. T. Chang and W. Wu: Mater. Trans., 49 (2008), 688.

23) T. Honeyands and J. Herbertson: Steel Res., 66 (1995), 287.

24) Y. Sahai and R. I. L. Guthrie: Metall. Trans. B, 13B (1982), 193. 